\title{
ОПРЕДЕЛЕНИЕ ПРОЧНОСТНЫХ СВОЙСТВ УГЛЕПОРОДНОГО МАССИВА ПО ДАННЫМ ГЕОФИЗИЧЕСКИХ ИССЛЕДОВАНИЙ СКВАЖИН (ЮЖНО-ЯКУТСКИЙ УГОЛЬНЫЙ БАССЕЙН)
}

\author{
П. Ю. Кузнецов ${ }^{1,2}$, Н. Н. Гриб $\sigma^{2,3}$, Г. В. Гриб ${ }^{2}$ \\ ${ }^{1}$ Филиал АО ХК «Якутуголь» Разрез «Нерюнгринский» \\ ${ }^{2}$ Технический институт (филиал) СВФУ, г. Нерюнгри \\ ${ }^{3}$ Академия наук Республики Саха (Якутия)
}

Поступила в редакцию 22 января 2019 г.

\begin{abstract}
Аннотация: в статье представлены результаты исследований авторов в области применения данных геофизических исследований скважин для определения прочностных свойств углепородного массива на примере Южно-Якутского угольного бассейна. Обозначена возможность оценки представительности исходных данных геофизических исследований скважин по диаграммам кавернометрии с иелью исключения возможности некорректного определения прочностных свойств углепородного массива и последующего их включения в базы данных, участвующие в компьютерном моделировании угольных месторождений. Также в статье рассмотрена, установленная в результате авторских исследований, аппроксимирующая функиия, позволяющая наиболее эффективно для условий Южно-Якутского угольного бассейна определять прочностные свойства углепородного массива по данным геофизических исследований скважин. Приведены расчетные уравнений для определения пределов прочности на одноосное сжатие и растяжение углевмещающих горных пород Южно-Якутского угольного бассейна по данным кавернометрии и гамма-каротажа. Установлены весовые коэффичиенты геофизических параметров для ряда угленосных районов Южно-Якутского угольного бассейна, повышаюшие точность определения пределов прочности на одноосное сжатие и растяжение углевмещающих пород. Представлены примеры оценки представительности исходных геофизических данных по данным кавернометрии и определения пределов прочности на одноосное сжатие и растяжение углевмещающих пород Эльгинского каменноугольного месторождения, входящего в состав Южно-Якутского угольного бассейна.

Ключевые слова: геофизические исследования скважин, прочностные свойства углепородного массива, оченка представительности исходных данных геофизические исследования скважин, методика определения прочностных свойств углевмещзающих пород, Южно-Якутский угольный бассейн.
\end{abstract}

\section{DETERMINATION OF COAL ROCK STRENGTH PROPERTIES ACCORDING TO GEOPHYSICAL WELL SURVEY ( THE SOUTH-YAKUT COAL BASIN)}

\begin{abstract}
: the article represents the research results in the field of data application of the geophysical well survey for determination of strength properties of coal massif by the example of the South-Yakut coal basin. The authors defined estimability of representativeness of the initial data of the geophysical well survey in accordance with the caliper logs with the aim of exception of wrong determination of the strength properties of the coal massif and their further inclusion in the database, used in computer modelling of coal deposits. The article considers the approximating function, established in the authors' research, which allows more efficient determination of strength properties of the coal massif in compliance to the geophysical well survey for the conditions of the South-Yakut coal basin. In addition, the authors represent calculating equations for determination of strength characteristics at uniaxial compression and extension of coal massif in the South-Yakut coal basin according to the data of caliper logs and gammaray logging. The authors determined weigh coefficients of the geophysical parameters for some coal bearing regions of the South-Yakut coal basin, increasing determination accuracy of ultimate strength at uniaxial compression and extension of the coal-bearing rocks. The article contains examples of estimation of the representativeness of the initial geophysical data according to the caliper logs and determina-
\end{abstract}


tion of the ultimate strength at uniaxial compression and extension of coal-bearing rocks of the Elginsk coal deposit, as a part of the South-Yakut coal basin.

Keywords: geophysical well survey, strength properties of coal massif, estimability of representativeness of the initial data of the geophysical well survey, determination method of strength properties of coalbearing rocks, the South-Yakut coal basin.

\section{Введение}

Учитывая современные тенденции интенсификации развития геоинформационных систем в компьютерном моделировании месторождений полезных ископаемых, реализуемом как на стадиях разведки, так и эксплуатации месторождений полезных ископаемых, возникает необходимость обеспечения этих систем максимально возможным полным объемом первичных данных о фактическом состоянии объекта моделирования. Именно такой подход, учитывая современное состояние развития геоинформационных систем, позволяет обеспечить возможность управления процессами эффективного исследования и эксплуатации месторождений полезных ископаемых.

Как правило, наборы первичных данных о фактическом состоянии месторождений полезных ископаемых требуют дополнительной обработки для получения достоверных информационных баз данных, используемых геоинформационными системами, при моделировании месторождений по интересующим показателям их состояния $[1,2,3]$. Одним из примеров такой обработки может служить методика определения прочностных свойств углепородного массива по данным геофизических исследований скважин (ГИС), разработанная и апробированная авторами для угольных месторождений Южно-Якутского угольного бассейна.

Целесообразность применения данных ГИС для определения прочностных свойств углепородного массива обусловлена рядом преимуществ по сравнению с традиционными видами их изучения [3-6]:

- ГИС обеспечивают непрерывное изучение разреза скважины, включая трещиноватые и легко разрушаемые породы, которые не удается количественно охарактеризовать при традиционных видах опробования (как правило, из-за низкого выхода керна);

- ГИС позволяют изучать прочностные свойства углепородного массива в его естественном залегании, что уменьшает влияние релаксационных процессов на конечный результат исследований состояния углепородного массива.

- ГИС охватываются все геологоразведочные скважины, что позволяет повысить информативность баз данных о прочностных свойствах углепородного массива, создаваемых на стадиях разведки и эксплуатации угольных месторождений.

В настоящее время, рассматриваемая в статье методика определения прочностных свойств углепородного массива по данным ГИС успешно была апробированная в ряде угленосных районов Южно-Якутского угольного бассейна: Токинский угленосный район (Эльгинское каменноугольное месторождение); Алдано-Чульманский угленосный район (каменноугольные месторождения: Нерюнгринское, Денисовское, Талу- минское, Чульмаканское); Усмунский угленосный район (Сылахское каменноугольное месторождение).

\section{Методика определения прочностных свойств} углепородного массива по данным ГИС

Основным положением методики является соответствие стадии литификации угленосных пород соответствующей стадии метаморфизма углей и необратимость физико-механических свойств пород, приобретенных в момент максимального погружения [5].

Учитывая, что в условиях Южно-Якутского бассейна на петрофизические свойства, в значительной степени, влияет фациально-стратиграфический фактор, приложено использовать метод гамма каротаж (ГК), поскольку величина естественной радиоактивности горных пород не зависит от постседиментационных преобразований [3].

С прочностными свойствами пород коррелирует их способность к разрушению при бурении, что находит свое косвенное отображение в изменении фактического диаметра скважин, поэтому при разработке методов использовались данные кавернометрии (КВ). Поэтому при разработке методики в основу положен комплекс, данные ГК и КВ (ГИС-2) [3].

Для эффективного применения методики определения прочностных свойств углепородного массива по данным ГИС необходимо оценить данные ГИС на возможное ограничение их применения с целью снижения риска получения недостоверной информации.

Необходимость проверки данных ГИС на возможное ограничение их применения связана с возможным наличием аварийных ситуаций, возникающих при проходке разведочных скважин. Как правило, ликвидация аварий приводит к дополнительному увеличению диаметров скважин, что в свою очередь ведет к возникновению грубых ошибок при сопоставлении и оценке наличия взаимосвязи между данными ГИС и прочностными свойствами углепородного массива. Таким образом, исходные данные ГИС перед их применением должны быть оценены на их представительность.

Оценку представительности исходных данных ГИС авторами предлагается производить на основе данных кавернометрии скважин. Применение для этой цели результатов кавернометрии обусловлено тем, что они зависят не только от степени разрушаемости пород при нормальных режимах бурения, но и от экстремальных режимов при ликвидации геологических осложнений, возникающих при бурении. Логично предположить, что ликвидация аварий при проходке скважины приведет к дополнительному увеличению ее диаметра, которое в свою очередь отразится аномально на данных кавернометрии и естественно к искажению значений зарегистрированной естествен- 
ной радиоактивности горных пород, в этих интервалах, поэтому, именно данные кавернометрии должны быть положены в основу подхода первичной оценке представительности исходных данных ГИС.

В качестве параметра оценки диаграмм кавернометрии, авторами рассматривается параметр $\xi$, определяемый в соответствии с формулой $[7,8]$ :

$$
\xi=1+\frac{d_{i}-d_{\text {заб }}}{40},
$$

где: $d_{i}$ - диаметр скважины в $i$-той точке наблюдения, мм; $d_{\text {заб }}$ - диаметр скважины на забое, мм.

Так как назначение данного параметра заключается в установлении зависимости отклонения диаметра скважины от режима бурения для каждой скважины в отдельности, то для возможности сопоставления скважин необходимо рассчитать усредненный параметр $\xi$, который характеризовал бы угольное месторождение в целом. Усреднение рекомендуется проводить по минимальным значениям диаметров скважин для интервалов шагом 20-40 м по всей совокупности имеющихся данных по кавернометрии. Такой подход обусловлен тем, что минимальные диаметры характеризуют наиболее прочные углевмещающие породы, которые с глубиной должны истираться равномерно относительно забоя скважины. Помимо усредненного параметра $\xi$ необходимо рассчитать его доверительный интервал изменения посредством стандартных методов математической статистики.

Сам процесс первичной оценки представительности исходных материалов по данным кавернометрии в каждой отдельной скважине сводится к оценке попадания рассчитанного параметра $\xi$ по глубине скважине в доверительный интервал усредненного параметра $\xi$. Если значения параметра $\xi$, рассчитанного для отдельной скважины, попадает в доверительный интервал усредненного параметра $\xi$, то принимается, что данные ГИС можно применять для определения прочностных свойств углепородного массива. На рис. 1 представлен пример разбраковки диаграмм кавернометрии скважин для условий Эльгинского каменноугольного месторождения. В соответствии с рис. 1 данные ГИС по скважинам № 1042 и № 1078 должны быть ограничены для дальнейшего применения при определении прочностных свойств углепородного массива с целью исключения получения некорректных данных.

Непосредственно сама методика определения прочностных свойств углепородного массива базируется на поиске многомерных корреляционных связей между параметрами ГИС и прочностными свойствами массива горных пород. Наиболее эффективной для условий Южно-Якутского угольного бассейна с точки зрения авторов, на основе ранее проведенных ими исследований $[3,8,9,10]$, для определения прочностных свойств углепородного массива по данным ГИС является аппроксимирующая функции вида:

$$
Y_{j}=\sum_{i=1}^{n}\left[B_{i j} \cdot 10^{\left(C_{i}+D_{i} \cdot X_{i}\right)}\right]
$$

где: $Y_{j}, X_{i}-$ соответственно физико-механические и геофизические параметры; $B_{i j}-$ коэффициент, учитывающий вес геофизического параметра; $C_{i}, D_{i}-$ коэффициенты полинома.

В качестве примера применения представленной выше аппроксимирующей функции можно привести результаты поиска расчетных уравнений для определения пределов прочности на одноосное сжатие и растяжение углевмещающих горных пород по данным кавернометрии (КВ) и гамма-каротажа (ГК). Для условий Южно-Якутского угольного бассейна эти уравнения имеют следующий вид $[8,9]$ :

$$
\begin{gathered}
\sigma_{\text {сж }}=B_{1} \cdot 10^{\left(3,1-1,3 \cdot \frac{I_{\gamma}-I_{\gamma}^{\min }}{I_{\gamma}^{\max }-I_{\gamma}}\right)}+B_{2} \cdot 10^{4,1-\frac{D-0,5 \cdot \Delta H^{-0,63}}{D_{n}}} \\
\sigma_{p}=B_{3} \cdot 10^{\left(2,1-1,3 \cdot \frac{I_{\gamma}-I_{\gamma}^{\min }}{I_{\gamma}^{\text {max }}-I_{\gamma}}\right)}+B_{4} \cdot 10^{3,1-\frac{D-0,5 \cdot \Delta H^{-0,63}}{D_{n}}}
\end{gathered}
$$

где: $\sigma_{\text {сж }}-$ предел прочности горных пород на одноосное сжатие, МПа; $\sigma_{p}$ - Предел прочности горных пород на одноосное растяжение, МПа; $I_{\gamma}, I_{\gamma}^{\min }$ и $I_{\gamma}^{\max }$ измеренное, минимальное и максимальное значение естественной радиоактивности в скважине, мкр/ч.; $D$ - диаметр скважины в точке измерения, мм; $D_{n}$ - номинальный диаметр скважины, мм; $B_{1}, B_{2}, B_{3}$ и $B_{4}-$ весовые коэффициенты геофизических параметров; $\Delta H$ - разница между глубиной скважины и глубиной, на которой производится измерение, м.

В случае применения представленных расчетных формул определения пределов прочности на одноосное сжатие и растяжение для конкретных угленосных районов Южно-Якутского угольного бассейна необходимо установить весовые коэффициенты геофизических параметров. Данные коэффициенты рассчиты- ваются методом наименьших квадратов с использованием фактических значений прочностных свойств горных пород, полученных по результатам лабораторных исследований, выполняемых с помощью полевых лабораторных станций (экспресс опробование) [3]. Применение полевых лабораторных станций обусловлено стремлением подойти к получению данных о прочностных свойствах углепородного массива в его естественном состоянии при снижении влияния на образцы горных пород релаксационных процессов, которые зачастую не учитываются при проведении лабораторных испытаний в стационарных лабораториях, удаленных, как правило, на значительные расстояния от мест отбора проб.

По результатам обработки данных полученных по экспресс опробованию и данных ГИС для условий 


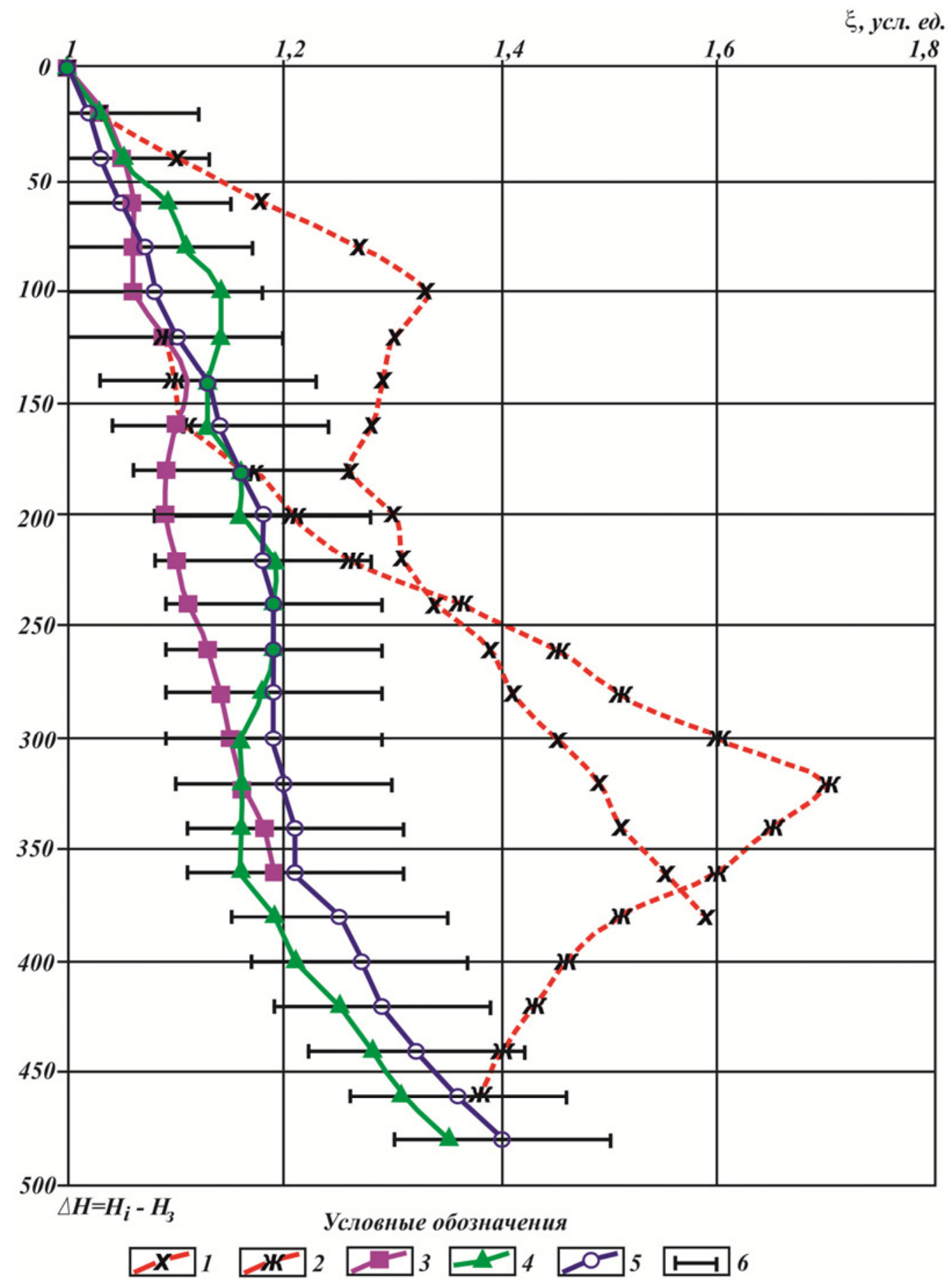

Puc. 1. Палетка разбраковки диаграмм кавернометрии для условий Эльгинского каменноугольного месторождения [7]: 1 - параметр $\xi$ скважины № 1078; 2 - параметр $\xi$ скважины № 1042; 3 - параметр $\xi$ скважины № 1018; 4 - параметр $\xi$ скважины № $1035 ; 5$ - усредненный параметр $\xi ; 6$ - доверительный интервал параметра $\xi ; \Delta H$ - расстояние от точки наблюдения до забоя скважины.

месторождений Токинского и Усмунского угленосных районов были установлены следующие весовые коэффициенты геофизических параметров: $\mathrm{B}_{1}=0,4605$; $\mathrm{B}_{2}=0,4605 ; \mathrm{B}_{3}=0,500 ; \mathrm{B}_{4}=0,500[8,9]$. Для условий месторождений Алдано-Чульманского угленосного района: $\mathrm{B}_{1}=0,5 ; \mathrm{B}_{2}=0,4 ; \mathrm{B}_{3}=0,500 ; \mathrm{B}_{4}=0,4[3,9]$.

Пример определения прочнстных свойств углевмещающих пород приведен на рис. 2.
Достоверность определения прочностных свойств по данным каротажа, устанавливалась путем сравнения с результатами лабораторных испытаний образцов керна (рис. 2).

Относительная среднеквадратическая погрешность определения прочностных свойств составляет : для $\sigma_{\text {сж }}-\delta=13 \%$, для $\sigma_{\mathrm{p}}-\delta=11 \%$. 


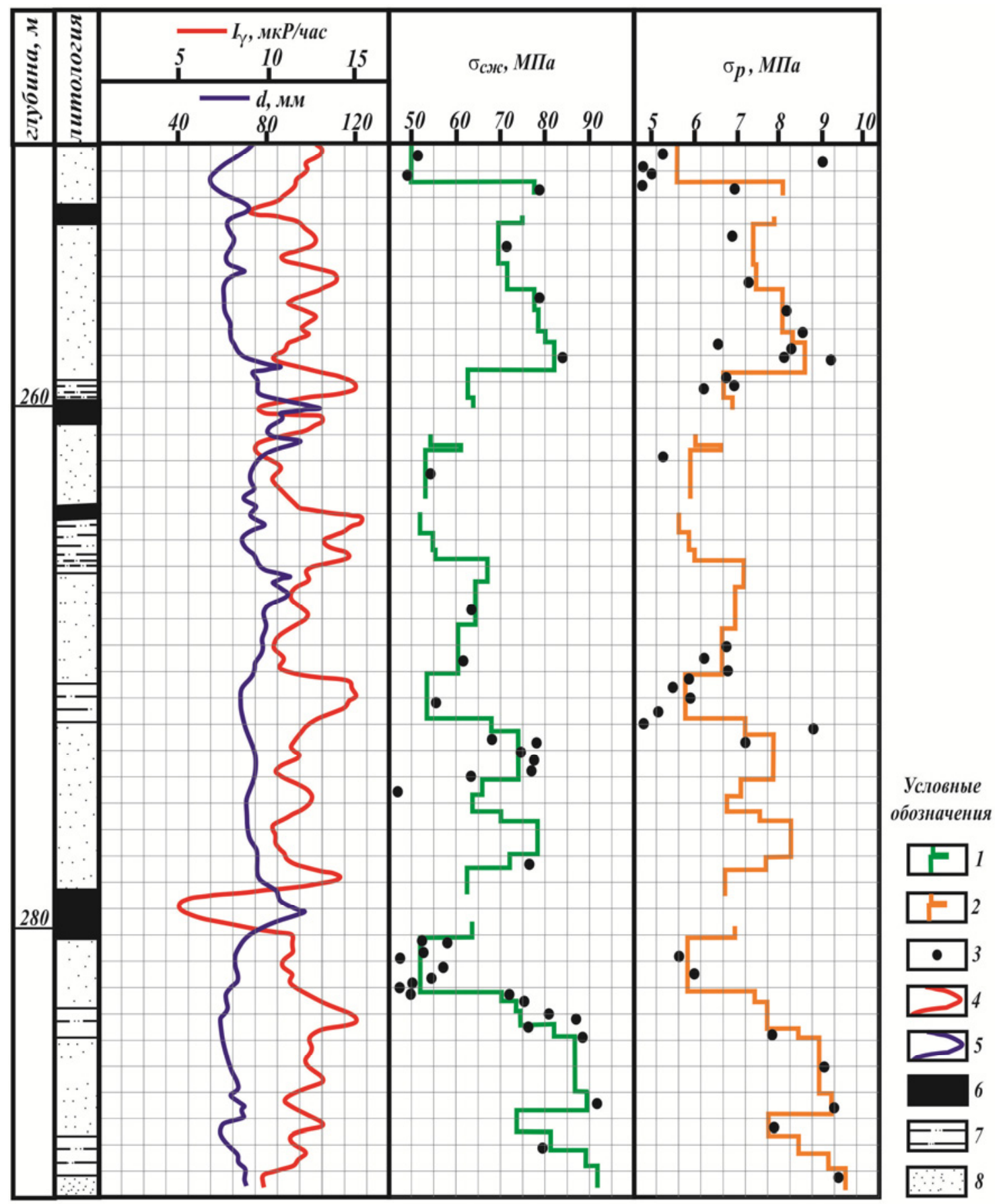

Puc. 2. Фрагмент графической интерпретации определения пределов прочности по данным геофизических исследований скважин: 1 - пределы прочности горных пород на одноосное сжатие, определенные по методике; 2 - пределы прочности горных пород на одноосное растяжение, определенные по методике; 3 - пределы прочности горных пород, определенные методом экспресс опробования; 4 - диаграмма гамма каротажа; 5 - диаграмма кавернометрии; 6 - уголь; 7 - алевролит; 8 песчаник.

\section{Заключение}

Применение данных ГИС с соблюдением процедуры оценки их представительности, для определения прочностных свойств углепородного массива позволяет значительно расширить информативность баз данных, формируемых на различных стадиях изучения угольных месторождений, посредством вовлечения в них достаточно большого объема первичных материалов исследования месторождений, которые, как правило, остаются невостребованными. Представленный подход к расширению баз данных за счет первичных исследовательских материалов в свою очередь позволит обеспечить повышение детальности компьютерного моделирования угольных месторождений, основанного на применении современных геоинформационных систем. 
Также стоит отметить, что на сегодняшний день, представленная в статье методика использования данных ГИС для определения прочностных свойств углепородного массива, успешно адаптирована и применяется в условиях Алдано-Чульманского и Токинского угленосных районов Южно-Якутского угольного бассейна. Наиболее эффективной областью применения представленной методики, как показала практика сотрудничества с горными предприятиями Южно-Якутского региона, является решение задач по созданию достоверных баз данных по прочностным характеристикам углепородного массива. Созданные в соответствии с представленной методикой базы данных обеспечивают на горных предприятиях реализацию мероприятий, направленных на повышения эффективности ведения буровзрывных работ и обеспечения устойчивости горных выработок.

\section{ЛИТЕРАТУРА}

1. Schön, J. H. Physical Properties of Rocks: Fundamentals and Principles of Petrophysics. / J. H. Schön. - Amsterdam: Elsevier, 2015. - $495 \mathrm{p}$.

2. Zhang, L. Engineering Properties of Rocks / L. Zhang. Amsterdam: Elsevier, 2017. - 378 p.

3. Гриб, Н. Н. Физико-механические свойства углевмещающих пород Южно-Якутского бассейна / Н. Н. Гриб, А.

Филиал ОАО ХК «Якутуголь» Разрез «Нерюнгринский» Кузнечов Павел Юрьевич, ведущий инженер по горным работам, кандидат геолого-минералогических наук E-mail: kuznetsov.pavel.yu@gmail.com; Тел.: 8 (41147) 91041

${ }^{1}$ Федеральное государственное автономное образовательное учреждение высшего образования Технический институт (филиал) федерального государственного автономного образовательного учреждения высшего образования «Северо-Восточный федеральный университет имени М. К. Аммосова», г. Нерюнгри

${ }^{2}$ Академия наук Республики Саха (Якутия)

${ }_{1,2}^{2}$ Гриб Николай Николаевич, заместитель директора по научной работе, профессор кафедры «Горное дело», доктор технических наук

E-mail: grib@nfygu.ru; Тел.: +7 (41147) 44938

${ }^{3}$ Научно-исследовательская лаборатория «Мониторинга и прогноза сейсмических событий»

${ }_{1,3}^{2}$ Гриб Галина Владиславовна, заведующий лабораторией, кандидат геолого-минералогических наук

E-mail: gv.grib@s-vfu.ru; Тел.: +7 (41147)63694
В. Самохин. - Новосибирск: Наука, Сиб. предприятие РАН, 1999. $-240 \mathrm{c}$.

4. Гречухин, В. В. Геофизические методы изучения геологии угольных месторождений/ В. В. Гречухин. - М. : Недра, 1995. $-476 \mathrm{c}$.

5. Гречухин, В. В. Петрофизика угленосных формаций/ В. В. Гречухин. - М. : Недра, 1990. - 468 с.

6. Menke, W. Geophysical Data Analysis: Discrete Inverse Theory: 4th Edition / W. Menke. - Academic Press, 2018. - 342 p.

7. Гриб, Н. Н. Прогнозирование физико-механических свойств углевмещающих пород на основе данных геофизических исследований скважин и математического аппарата Марковской нелинейной статистики / Н.Н. Гриб, П.Ю. Кузнецов // Уголь. - 2018. - №1. - С. 68-73.

8. Кузнецов, П. Ю. Оценка пространственной изменчивости свойств массива горных пород для оптимизации сети инженерно-геологических скважин при разведке угольных месторождений (на примере Эльгинского месторождения): автореф. дис ... канд. геол.-минер.. наук: 25.00.16 / П. Ю. Кузнецов. -Томск, 2005. - 24 с.

9. Гриб, H. H. Разработка методов прогнозирования технологических характеристик углей, литологического состава и физико-механических свойств углевмещающих пород Южно-Якутского бассейна по геофизическим данным: автореф. дис. ... д-ра. техн. наук: 05.15.11 / Н. Н. Гриб. - Кемерово, 1999. - 49 с.

10. Прогноз устойчивости углевмещающих пород по геофизическим данным / Н. Н. Гриб [и др.] // Фундаментальные исследования. - 2013. - №6-2. - С. 397-401.

Branch of SC HC «Yakutugol» Opencast coal mine «Neryungrinskiy»

Kuznetsov P. Yu., leading mining engineer, candidate of geological and mineralogical sciences

E-mail: kuznetsov.pavel.yu@gmail.com

Tel.: +7 (41147) 91041

${ }^{1}$ Technical Institute (branch) of North-Eastern Federal University named after M. K. Ammosov, Neryungri

Grib N. N., deputy director for science, professor of the mining department, Technical institute (b) NEFU, Prof. Dr-Ing.

E-mail: grib@nfygu.ru

Tel.: +7 (41147) 44938

${ }^{2}$ Scientific - research laboratory «Monitoring and prediction of seismic events»

${ }^{1,2}$ Grib G. V., chief of laboratory, Candidate of the Geological and Mineralogical Sciences

E-mail:gv.grib@s-vfu.ru

Tel.: +7 (41147) 63694 